\title{
Public health security - caring for the health of populations?
}

In September 2000, the United Nations Millennium Declaration was signed and the Millennium Development Goals (MDGs) were derived from this declaration. At the same time as the Sustainable Development Goals and MDGs were being developed, there was a growing awareness of the potential role of infectious diseases - and specifically epidemics and pandemics - in national security. ${ }^{[1]}$ In 2000, the National Intelligence Council produced a report entitled The Global Infectious Disease Threat and Its Implications for the United States. ${ }^{\left[{ }^{[2]}\right.}$ This was USA-specific and focused on the extent to which the 'growing global infectious disease threat' would affect the USA, both within the continent and also its activities and influence elsewhere in the world. Infectious diseases are then seen through a 'national security lens', e.g. tropical disease research conducted by the US Department of Defense's Institutes is motivated by the 'security interest' to understand infectious diseases that threaten military personnel abroad. This was at a time when even the World Health Organization (WHO) in its 1999 World Health Report ${ }^{[3]}$ said that it 'does not make economic sense to try to provide comprehensive medical services for everyone. The overarching philosophy was that the provision of healthcare must be 'cost-effective' and that 'effective treatment is too expensive to be considered "realistic" in resource-poor settings' - leading to acceptance of a lower standard of care - setting resource-poor countries up for health-related problems, poor response to emergencies, etc. ${ }^{[1]}$ Which has of course been seen with the increasing numbers of outbreaks and emergencies and consequent population movements and increasing poverty - and then there is climate change as well.

With the publication of The World Health Report 2007: A Safer Future - Global Public Health Security in the 21st Century, ${ }_{,}^{[4]}$ the importance of public health security in the control of disease globally became mainstream thinking. Public health security was defined in the report as 'the activities required, both proactive and reactive, to minimize vulnerability to acute public health events that endanger the collective health of populations living across geographical regions and international boundaries'. The report emphasised the importance of the International Health Regulations (IHR) 2005 as the international legal instrument designed to achieve maximum security against international spread of diseases, specifically with its focus on a proactive approach to infectious disease control.

The end result of this is that bodies such as the WHO set norms and standards, in the framework of IHR 2005, with the specific intention of improving 'public health security', and programmes within the WHO are specifically tasked with helping countries in the developing world to adhere to these in order to do so. But is this actually improving public health and more specifically, people's access to healthcare?

Let's take the current Ebola virus disease (EVD) outbreak in the Democratic Republic of the Congo (DRC) as an example. Starting in August 2018 and still ongoing, albeit at a much lower level, this is the worst EVD outbreak in DRC since the 2014 - 2016 outbreak in West Africa. And not for lack of response, which was the fastest, best equipped and best funded in the history of Ebola outbreak response. ${ }^{[5]}$ So what has gone wrong? Reading a report prepared earlier this year to specifically ask this question, ${ }^{[5]}$ it is clear that the emphasis of the response is on 'public health security' and not on the welfare of the affected population. Talking to colleagues working in the WHO Health Emergencies Programme in Brazzaville in November 2019, their anecdotes were telling. When the Director-General of the WHO,
Tedros Adhanom, visited one affected community he was asked 'Is your interest because you care about us, or because you are worried that the disease will spread to your country?' His response, 'Both', was refreshingly honest, but unwittingly encapsulates one of the main problems. The Independent Oversight and Advisory Committee for the WHO Health Emergencies Programme points out that the communities in question have been neglected by their government and by the broader aid partner community for decades. ${ }^{[5]}$ Under normal circumstances they have little or no access to healthcare, and what they do have has to be paid for. Now, with EVD, they have free healthcare, but if someone with cholera arrives at an Ebola treatment centre they are turned away. They were not allowed to vote in the recent elections in DRC because of fears of spread of the disease in large gatherings. Their communities are isolated in forest areas, with poor roads and communications, and they have been struggling with insurgent attacks and insecurity for many years, which has been ignored by both local and international authorities, only making headlines when it affects the Ebola response. The report's recommendations are important and innovative, but what stands out is something fundamental - ensure good access to stable, well-equipped healthcare services across the entire country, preferably free at the point of service. In other words, fix the country's health infrastructure. Even in the complex situation in Ituri and North Kivu, DRC, this would have gone a long way to ensuring that these rapid response measures worked.

This applies across Africa, where in most countries people pay for healthcare access except in outbreaks of infectious diseases that threaten to cross borders. So what lessons am I taking away from this for my own country, South Africa (SA)? Here we do have reasonable health infrastructure, albeit variable across the country. And SA is one of the WHO Member States that are pretty compliant with the IHR 2005 requirements. But it took us many months to identify the source of the recent listeriosis outbreak, far longer than it should have done for a country with our resources, and too many people died. We are indeed vulnerable. Adherence to norms and standards is relatively easy to show on paper, in committees and in policy documents. What is needed is the will to actually make a difference to people's lives.

\section{Bridget Farham}

Editor

ugqirha@iafrica.com

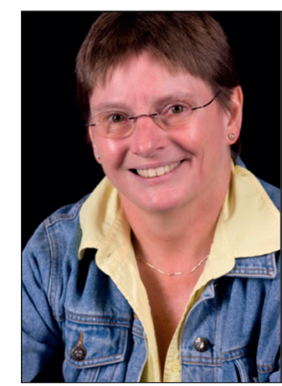

Bensimon CM, Benatar SR. Developing sustainability: A new metaphor for progress. Theoretical Medicine and Bioethics 2006;27(1):59-79. https://doi.org/10.1007/s11017-005-5754-1

National Intelligence Council. The Global Infectious Disease Threat and Its Implications for the United States. NIC, 2000. https://www.dni.gov/files/documents/infectiousdiseases_2000.pdf (accessed 3 December 2019).

World Health Organization. The World Health Report 1999 - Making a Difference. Geneva: WHO 1999. https://www.who.int/whr/1999/en/whr99_en.pdf?ua=1

4. World Health Organization. The World Health Report 2007: A Safer Future - Global Public Health Security in the 21st Century. Geneva: WHO, 2007. https://www.who.int/whr/2007/whr07 en.pdf?ua= 1 (accessed 1 December 2019).

5. Independent Oversight and Advisory Committee for the World Health Organization Health Emergencies Programme. From 'never again' to the 'new normal': What does the 2018 - 2019 Ebol outbreak in the Democratic Republic of the Congo tell us about the state of global epidemic and outbeak in the Danes and response? 2019. hongs tapps who pdf (accessed 3 December 2019). 